\title{
Household Demand and Willingness to Pay for Solid Waste Management Service in Tuobodom in the Techiman-North District, Ghana
}

\author{
Kwetey Seth, Samuel Jerry Cobbina*, Wilhemina Asare, Abudu Ballu Duwiejuah \\ Department of Ecotourism \& Environmental Management, Faculty of Renewable Natural Resources, University for Development \\ Studies \\ *Corresponding author: cobbinasamuel@yahoo.com
}

Received August 07, 2014; Revised August 21, 2014; Accepted September 10, 2014

\begin{abstract}
The study was to examine whether respondents' demographic characteristics (sex, age, educational level, income and employment) could affect the willingness to pay for waste management services in Tuobodom in the Techiman-North District of Ghana. The quota, systematic and convenience sampling techniques were employed in the selection of the 200 respondents. Even though many respondents demanded for improved waste management services, the study revealed that majority of the respondents (62\%) were unwillingness to pay for the waste management services and 38\% were willing to pay for waste services. The study observed illicit burning, open dumping of waste and lack of waste collection containers to receive refuse in the Tuobodom community which might be the reasons for their unwillingness to pay for improved waste management service. Probit analysis reveals that respondent's socio-economic characteristics such as age, education, income and employment has no significant influence in the respondent's willingness to pay for improved waste service. Based on the findings of this study, it is therefore recommended that the Techiman-North District Assembly should provide waste collection containers to receive waste generated to curb the menace of solid waste disposal that threatened the achievement of the seventh Millennium Development Goals.
\end{abstract}

Keywords: probit analysis,willingness to pay,Tuobodom, solid waste

Cite This Article: Kwetey Seth, Samuel Jerry Cobbina, Wilhemina Asare, and Abudu Ballu Duwiejuah, "Household Demand and Willingness to Pay for Solid Waste Management Service in Tuobodom in the Techiman-North District, Ghana." American Journal of Environmental Protection, vol. 2, no. 4 (2014): 74-78. doi: 10.12691/env-2-4-3.

\section{Introduction}

Sustainable solid waste management is crucial problem not only for developing countries but also developed countries as well. Waste management practices especially the municipal solid waste can differ for developed and developing nations, for urban and rural areas, and for residential, commercial and industrial producers. Waste collection methods vary widely among different countries and regions. Domestic waste collection services are often provided by local government authorities, or by private companies in the urban cities. Countries and experts alike spend lot of time and resources to come out with a solution to the problem of environmental degradation and climate change. A problem created by mankind due to thoughtless act of consumerism [1].

Community participation has a direct bearing on efficient solid waste management. Yet, the municipal authorities have failed to mobilize the community and educate citizens on the rudiments of handling waste and proper practices of storing it in their own bins at the household, shop and establishment level [2]. According to
[3], solid waste generation is an increasing global environmental and public health problem. The rapid uncontrolled, unplanned urbanization in the developing nations of Africa has brought untoward ill effect of environmental degradation. Indeed, one of the most pressing concerns of urbanization in the developing world has been the problem of solid, liquid and hazardous-waste management. Recent events in major urban areas in Africa have shown problem of waste management to be a monster that has aborted efforts of both federal governments and many professionals [4].

According to [5], nine out of ten African cities are facing serious waste problems. In developing countries, municipal solid waste is not well managed because cities and municipalities cannot cope with the accelerated pace of waste production [6]. This global threat of solid waste disposal has shown its ugly face in Africa. Due to lack of appropriate planning, inadequate governance, resource constraint, and ineffective management, solid waste especially insufficient collection and improper disposal of itis a major concern for many rapidly growing cities in developing countries [7]. The swift expansion of urban agricultural and industrial activities, stimulated by population growth, has produced vast amounts of solid 
and liquid wastes that pollute the environment and destroy resources. Changing economic trends and rapid urbanization also complicate solid waste management (SWM) in developing countries. Consequently, solid waste is not only rising in quantity but also changing in composition (from less organic matter to more paper, packing materials, plastics, glass, metal, and other substances), which is exacerbated by low collection rates [8]. Rapid population growth and urbanization in general have led to serious solid waste generation in most cities worldwide. Municipal solid waste globally, increased by at least 7\% annually between 2003 and 2006 [9].

The privatization of the solid waste collection services is actively being pursued by local government authorities in the urban cities while the semi-rural and rural areas are offering the traditional free social services through the private sector. The current free waste collection services are not sustainable, considering the challenges faced by cities (city) authorities in introducing fee-based waste collection systems [10]. Environmental services strategies which solely depend on government funding are not sustainable and therefore waste generators contribution in funding waste collection activities is crucial. Willingness to pay for waste management services or facilities is very important to the success of the private sector's participation in solid waste management program. The willingness to or not to pay have direct impact (positive or negative) on the reliability and success of any solid waste management strategy [11].

The current environmental sanitation status of Ghana leaves much to be desired. Less than $40 \%$ of urban residents are served by a solid waste collection services, less than 30\% have acceptable household toilet facility [12], and only about $10 \%$ of solid wastes generated are properly disposed [13], with rural dwellers less well served [12]. In rural areas and small towns, there are often no vehicles for collection of waste, hence uncontrolled dumping occurs within the built areas with all attendant health hazards and negative environmental impact [13]. Government funding cannot sustain the collection of waste in the District. In the Techiman-North District, a lot of stakeholders have suggested private sector involvement on a fee-paying basis [14].

Some studies have shown that the willingness to pay for solid waste management services is associated with income, education, quantity of waste generated, household size, and age [15]. However, little is known about the determinants of willingness to pay and demand for solid waste management services in semi-rural areas like Tuobodom. The proposition that rural and semi-rural people are unwilling and lack the ability to pay for solid waste collection services is just a generalized assumption which may apply to all rural communities. Generally, many studies in recent time have focus on urban areas and cities with little known about the determinants of willingness to pay for solid waste collection among semi rural-urban communities. This study was to examine possible factors that influence the inhabitants of semi-rural community willingness to pay and demand for solid waste management service.

\section{Materials and Methods}

\subsection{Study Area}

Tuobodom is the district capital of the Techiman-North Districtin the Brong-Ahafo region of Ghana. The District shares boundary with Techiman Municipality to the south, and Kintampo South to the north. Tuobodom is a farming community and was part of the Techiman Municipality until it was elevated to the status of a District Assembly in June, 2012. The district experiences both semi-equatorial and savannah climates characterised by moderate to heavy rainfall annually. The major rains starts from April to July, and the minor from September to October. Then the long dry season, which is highly pronounced in the November and lasts until March. There are two main relief features in the district, namely highlands points (about $579 \mathrm{~m}$ above sea level), while the lowest point of the district (about 305 $\mathrm{m}$ above sea level). Basically three main vegetation zones, namely, the Guinea-Savannah woodland located in the North-West, the Semi-Deciduous zone in the South, and the Transition zone which stretches from the South-East and West up to the North of the district [14].

\subsection{Data Collection, Sampling Technique and Data Analysis}

A total of 200 households were selected for questionnaire administration. This constitutes about $10 \%$ of the total households in Tuobodom. The technique used to sample respondents from various households were the quota, systematic and convenience sampling. The quota technique was used to allot proportionate number of 33 subjects to each of the six electoral areas within the Tuobodom community, while systematic technique was used to select housing units in each of the areas from which subjects were sampled. The 33 housing units were selected systematically. To select the individual respondents from the selected housing units, the convenience sampling technique was then employed. One female each was selected from the first two housing units. Then a male was selected from the third housing unit. This was repeated until individuals were selected from all the 33 housing units in the six electoral areas. Probit analysis was conducted using SPSS version 16.0 to established determinants of willingness to pay for improved waste management services.

\section{Results and Discussion}

\subsection{Socio-economic Characteristics of Respondent and Willingness-to-Pay for Waste Service}

Socio-economic characteristics were investigated and analysed to ascertain respondents' willingness to pay and demand for improved solid waste management service. The female account for $67 \%$ while $33 \%$ were male (Table $1)$. The age range with the highest frequency is $18-29$ years thus $41 \%$ of the respondents while those above 53 years accounted for $4 \%$. The average age of respondents was 46.5 years. This implies that respondents are in their active age and therefore can work to earn more income which can influence their decision to pay for improved waste services. The study revealed that sex and age of household respondent have no significant effect on 
willingness to pay for improved waste management service. This disagrees with $[16,17]$ that reported that the decision to pay for solid waste management services is influenced by gender and age.

About 28\% had no formal education, $41 \%$ of respondents had basic (Primary, Junior Secondary/High School) education and $31 \%$ had secondary and tertiary education (Table 1). Significant proportions (28\%) were illiterates who willingness to pay and demand for improved waste management service could be compromised, thereby likely to result in unhealthy behaviour. Level of education is a key factor in determining the willingness to pay for waste collection services. Education helps to enlighten the respondents on the need to keep the environment clean, free from germs and healthy for all. However, the low level of education has strongly influences their decision not to pay for improved waste management service. This account for about $37 \%$ of respondents perceiving that taxes paid are used to pay the waste management services. This is similar with [18] that stated that people think waste services is paid for through taxes or even considered as a social service to be paid by the government.

The occupational distribution of the respondents indicates that $3 \%$ of respondents were unemployed, $81 \%$ were self-employed, 9\% public servants and 7\% were employed in private companies (Table 1). About 68\% of the respondents were found to receive between GH\$200299 per month, 11\% receive above GH $\$ 400$ per month, $8 \%$ receive $\mathrm{GH} \$ 100-199$ per month, $7 \%$ receive $\mathrm{GH} \$ 300$ 399 per month and 6\% received GH\$0-99 per month (Table 1). The study revealed that majority of the respondents (62\%) were unwillingness to pay for the waste management services and 38\% were willing to pay for improved waste management services. In contrast, [19] reported about $57 \%$ households are willing to pay for improved services while $43 \%$ are unwilling to pay for improved services in the Kumasi. Generally, solid waste is usually dumped at communal collection points, open spaces or in the open gutters. The study observed illicit burning, open dumping of waste and lack of waste collection containers to receive refuse in the Tuobodom community which might be the reasons for their unwillingness to pay for improved waste management service. The study revealed that people with higher education seem to be willing to pay for improved waste service in the Tuobodom. The study shows that the respondents are with very minimal disposable income or under low income hence one of the reasons for unwillingness to pay for waste management services. This is in line with $[20,21,22]$ that reported that a combination of poverty, economic hardships and financial constraints undoubtedly are factors that contribute to improper solid domestic waste management.

Table 1. Socio-economic Characteristics of Respondent and Willingness-to-Pay for Waste Service

\begin{tabular}{|c|c|c|c|}
\hline \multirow[b]{2}{*}{ Socioeconomic variables } & \multicolumn{3}{|c|}{ WTP for improved solid waste management } \\
\hline & Variables & Frequency & Percentage \\
\hline \multirow[t]{2}{*}{ Gender } & Male & 66 & $33 \%$ \\
\hline & Female & 134 & $67 \%$ \\
\hline \multirow[t]{4}{*}{ Age } & $18-29$ & 82 & $41 \%$ \\
\hline & $30-41$ & 74 & $37 \%$ \\
\hline & $42-53$ & 36 & $18 \%$ \\
\hline & above 53 & 8 & $4 \%$ \\
\hline \multirow[t]{3}{*}{ Educational level } & None & 56 & $28 \%$ \\
\hline & Primary and Jun. Sec/High & 82 & $41 \%$ \\
\hline & Sen. Sec/High and Tertiary & 62 & $31 \%$ \\
\hline \multirow[t]{4}{*}{ Employment } & Civil servant & 18 & $9 \%$ \\
\hline & company employed & 14 & $7 \%$ \\
\hline & Self-employed & 162 & $81 \%$ \\
\hline & Unemployed & 6 & $3 \%$ \\
\hline \multirow[t]{5}{*}{ Income Distribution } & Very low (GHÆ 0-99) & 12 & $6 \%$ \\
\hline & Low (GHథ 100-199) & 16 & $8 \%$ \\
\hline & Average (GHÆ 200-299) & 136 & $68 \%$ \\
\hline & High (GHণ 300-399) & 14 & $7 \%$ \\
\hline & Very high (GHథ 400) & 22 & $11 \%$ \\
\hline
\end{tabular}

\subsection{Household Demand for Waste Management Services}

The study revealed that about $61 \%$ of the respondents prefer the low cost method, 33\% of the respondent also prefer the medium cost method while only $6 \%$ demanded for the high cost method (Table 2). About $90 \%$ of the respondents demanded that waste should be collected early in the morning before 8.00 am and $78 \%$ of the respondents demanded that waste should be collected once a day. The study revealed that $61 \%$ of the respondents (122) are willing to have a communal container (low cost system). Out of the 122 respondents who were demanding for the low cost method, 62\% preferred metal containers as against 35\% who opted for plastic containers (Table 2). With the low cost method (122), a large communal container is placed in the catchment area for refuse from individual houses. With the medium cost method (67), a vehicle would come to the neighbourhood on a scheduled basis to collect solid waste at each block or road junction, 
with added fee. As with the higher cost system (12), a vehicle comes to the neighbourhood on a schedule basis and provides a door-to-door service. At each building, container of waste which has been left at the curb side would be emptied.

Table 2. Demand for Improved Service Delivery

\begin{tabular}{|c|c|c|c|}
\hline \multirow{2}{*}{ Service } & \multicolumn{3}{|c|}{ WTP for improved solid waste management } \\
\hline & Variables & Frequency & Percentage \\
\hline \multirow[t]{2}{*}{ Willingness to pay } & Yes & 76 & $38 \%$ \\
\hline & No & 124 & $62 \%$ \\
\hline \multirow{4}{*}{ Containers } & Metal dustbin & 124 & $62 \%$ \\
\hline & Plastic dustbins & 62 & $31 \%$ \\
\hline & Plastic nylon/ bags & 10 & $5 \%$ \\
\hline & Others & 4 & $2 \%$ \\
\hline \multirow[t]{3}{*}{ Collection method } & Low cost & 122 & $61 \%$ \\
\hline & Medium cost & 66 & $33 \%$ \\
\hline & High cost & 12 & $6 \%$ \\
\hline \multirow[t]{4}{*}{ Time } & Early morning before 8.00am & 98 & $49 \%$ \\
\hline & Anytime in the morning & 90 & $45 \%$ \\
\hline & Anytime in the afternoon & 8 & $4 \%$ \\
\hline & Anytime in the day & 4 & $2 \%$ \\
\hline \multirow[t]{4}{*}{ Number of service delivery } & Once a day & 156 & $78 \%$ \\
\hline & Twice a day & 36 & $18 \%$ \\
\hline & Once a week & 6 & $3 \%$ \\
\hline & Twice a week & 2 & $1 \%$ \\
\hline
\end{tabular}

\subsection{Determinants of Willingness to Pay for Waste Management Services}

The determinants of the willingness to pay for improved waste management system have been widely suggested to have significant influence on the willingness of the respondents to pay for waste collection. However, probit analysis reveals no significant relationship exists between the respondents' willingness to pay for waste management services and the respondent's socioeconomic characteristics such as age, education, income and employment. This suggests that the respondents' willingness to pay for waste management services is not strongly tied to the socio-economic characteristics. This study therefore disagrees with $[23,24,25]$ that reported that sex, age, work, income and education affect willingness to pay for waste management services.

It is obvious that the indigenes of Tuobodom unwillingness to pay for improved waste management services are not strongly influenced by socio-economic characteristics. The study revealed that the waste management department in the Tuobodom has been confronted with logistics problem, inadequate personnel, lack of sanitary landfill site and lack of incentives for the few personnel. Basically, the District Assembly solely finances the waste management activities in the District. Open dumping and illicit burning are the commonest disposal methods practiced in the community. This indicates that achieving the MDGs goal seven (ensuring environmental sustainability) will be a merge since Tuobodom community is yet to be provided with waste management service that will influence their willingness to pay for effective waste management service and environmental protection. The solid waste disposal menace can lead to waste related problems such as offensive odour, fire outbreaks and causes air, water and sanitation related diseases and land pollution. There are no waste collection containers to receive refuse and residents do not pay for waste disposal services. The study agrees with [13] that reported that open in rural areas and small towns, there are often no vehicles for collection of waste, hence uncontrolled dumping occurs within the built up areas with all its attendant health hazards and negative environmental impact.

Table 3. Determinants of Willingness to Pay Improved For Waste Management Services

\begin{tabular}{cccccc}
\hline Variable & coefficient & Std. Error & Z-value & Sig. & \multicolumn{2}{c}{ Lower Bound } \\
\hline Age & & & & & -0.05 \\
Education & 0.05 & 0.05 & 0.96 & 0.34 & -0.18 \\
Employment & -0.07 & 0.06 & -1.19 & 0.24 & -0.37 \\
Income & 0.13 & 0.12 & -1.10 & 0.27 & -0.14 \\
Intercept & 0.87 & 0.09 & 0.38 & 0.71 & 0.12 \\
\hline
\end{tabular}

a. PROBIT model: PROBIT(p) = Intercept + BX

\section{Conclusion}

The willingness to pay is important for delivery of every social service including solid waste collection. The present study revealed that respondent's level of education, income, age and occupation have no significant influence on the willingness of the respondents to pay for improved waste management. However, the study observed that factors such as illicit burning, open dumping of waste and lack of waste collection containers to receive refuse in the Tuobodom community might be the reasons for their unwillingness to pay for improved waste management service.

The study also revealed that the waste management department in the Tuobodom has been confronted with logistics problem, inadequate personnel, lack of sanitary landfill site and lack of incentives for the few personnel. Basically, the District Assembly is solely responsible for the financing of the waste management activities in the District. This indicates that achieving the MDGs goal seven (ensuring environmental sustainability) will be a merge since Tuobodom community is yet to be provided with waste management service that will influence their willingness to pay for effective waste management service 
and environmental protection. The solid waste disposal menace can lead to waste related problems such as offensive odour, fire outbreaks and causes air, water and sanitation related diseases and land pollution. Based on the findings of this study, it is recommended that the Techiman-North District Assembly should provide communal containers to receive waste generated to curb the menace of solid waste disposal that threatened the achievement of the seventh Millennium Development Goals (the achievement of this blue-print target date of 2015).

\section{Acknowledgement}

The Authors would like to thank all Staff of Environmental Health and Sanitation Unit and Waste Management Department in Techiman-North District for their assistance in conducting the research work.

\section{Conflict of Interests}

The authors declare that there is no conflict of interests regarding the publication of thispaper.

\section{Reference}

[1] Sebastian,K. V. (2010). A study on the entrepreneurial traits and characteristics of waste pickers and their contributions to the economy and ecology. MPhil thesis submitted to Christ University, Bangalore.

[2] Asanani,P. U. (2006). Solid waste management, in India infrastructure report, New Delhi: 3i Network, Oxford, 160-189, 2006.

[3] UNEP (United Nations Environment Program), (2004). The Use of Economic Instruments in Environmental Policy: Opportunities and Challenges. Geneva: UNEP.

[4] Onibokun,A. G. (1999). Managing the monsters: urban waste and governance in Africa. International Development Research Centre, Ottawa.

[5] Lyse, O. (2003). Waste disposal haunts cities. The Times of Zambia (Ndola). Retrieved from Allafrica.com/stories.

[6] Modak, P. (2010).Municipal Solid Waste Management: Turning waste into resources. Shanghai Manual-A Guide for Sustainable Urban Development in the $21^{\text {st }}$ Century. Retrieved fromhttp://www.un.org/esa/dsd/susdevtopics/sdt_pdfs/shanghaima nual/Chapter\%205\%20\%20Waste_management.pdf, 2010.

[7] Chuen-Khee, P. \&Othman, J. (2010). Household Demand for Solid Waste Disposal Options in Malaysia. World Academy of Science, Engineering and Technology, 66, 1153-1158.

[8] Medina, M. (2002). Globalization, Development, and Municipal Solid Waste Management in Third World Cities. El Colegio de la Frontera Norte [College of the northern border], Tijuana, Mexico. Unpublished paper. http://depot.gdnet.org/gdnshare/pdf/2002AwardsMedalsWinners/
OutstandingResearchDevelopment/martin_medina_martinez_pape r.pdf. (Accessed January 2013).

[9] United Nations Environment Programme (UNEP). (2009) Developing Integrated Solid Waste Management Plan. Assessment of Current Waste Management System and Gaps therein.

[10] McDougall,F. White, P. Franke, M \&Hindle, P. (2001). Integrated Solid Waste Management: A Life Cycle Inventory. Blackwell Science, London.

[11] Rahman, M., Salequzzaman, M. D.,Bahar, M.,Uddin, N.,Islam,A \& Al Hrun, A. Y. (2005). People's perception of the existing solid waste management of Khulna City Corporation (KCC) Area: A case study of participatory management. Proc. National Workshop for REGA and CDM Awareness \& Motivation under the ADB PREGA Project. Bangladesh Centre for Advanced Studies, Khulna. www.adb.org?Documents/Evwnts/2005/AwarenessMotivationPhase2/Khulna/mrahaman.pdf, 2005.

[12] Boadi,K. O. \&Kuitunen, M. (2004). Municipal Solid Waste Management in the Accra Metropolitan Area. Environmentalist Journal, 23 (3), 112-132.

[13] Mensah, A \& Larbi, E. (2005). Solid waste disposal in Ghana. Well Fact sheet-Regional Annex. November.

[14] TNDA (2013). Personal communication. 24 $4^{\text {th }}$ March, 2013 at 1.45 $\mathrm{pm}$.

[15] Alta, A. A. \& Deshaz,O. J. (1996). Households Demand for improved solid waste management, a case study of Gujarwala Pakistan. Word Dev., 24 (5), 857-868.

[16] Ekere, W., Mugisha, J. \&Drake, L. (2010). Willingness to pay for sound waste management in urban and peri-urban areas of the Lake Victoria crescent region Uganda. Second RUFORUM Biennial Meeting 20-24 September 2010, Entebbe.

[17] Banga,M., Lokina, R. B., \&Mkenda, A. F. (2011). Solid Waste Collection Services in Kampala City, Uganda. The Journal of Environment Development. 20 (4), 428-448.

[18] Merton, R. K. (1968). Social structure and anomie in social theory and social structure", New York. Free Press.

[19] Awunyo-Vitor, D., Ishak, S. \&Jasaw, G. S. (2013). Urban Households' Willingness to Pay for Improved Solid Waste Disposal Services in Kumasi Metropolis, Ghana. Urban Studies Research, 2013, 8, 2013. http://dx.doi.org/10.1155/2013/659425.

[20] Satterth waite, D. (1998). Environmental problems in cities in the south: Sharing my confusions. In, Fernandes Edesio (Ed), Environmental strategies for sustainable development in urban areas. Lessons from Africa and Latin America. Ashgate Publishing Ltd, England.

[21] Tsiboe, I. A. \& Marbell, E. (2004). A look at urban solid waste disposal problem in Accra, Ghana. Unpublished Master's Thesis submitted to Roskilde University.

[22] Yusuf, S. A. \&Salimonu, K. (2007). Determinants of Willingness to Pay for Improved House Solid Waste Management in Oyo State, Nigeria. Research Journal of Applied Sciences, 2, 233-239.

[23] Cairncross,S. (1990). Water Supply and the Urban Poor. In: Hardoy, J.E., S. Cairn cross and D. Satterth waite (Eds.), the Poor Die Young: Housing and Health in Third World Cities. 1st Edn, Earths can Publications, London, 109-126. ISBN: 13: 9781853830198.

[24] World Bank (1995). Towards Sustainable Management of Water Resources. World Bank Publications, Washington. ISBN: 13: 9780821334133.

[25] Rahji,M. A. Y. \& Oloruntoba, O. (2009). Determinants of households' willingness-to-pay for private solid waste management services in Ibadan, Nigeria. Waste Manage Res December. 27 (3), 961-965, 2009. 